\title{
Research Paper: \\ Comparison of Total Salivary Antioxidants in Smokers and Non-smokers With Chronic Periodontitis
}

\author{
*Leila Golpasandhagh ${ }^{1}$, Seyied Mohammad Ghaffari ${ }^{2} \oplus$, Mahsa Bahadori ${ }^{1}$
}

1. Department of Periodontics, School of Dentistry, Ahvaz Jundishapur University of Medical Sciences, Ahvaz, Iran. 2. Department of Biochemistry, School of Medicine, Ahvaz Jundishapur University of Medical Sciences, Ahvaz, Iran

\begin{tabular}{c|l}
$\begin{array}{c}\text { Use your device toscan } \\
\text { and read the artice online }\end{array}$ \\
Citation Golpasandhagh L, Ghaffari SM, Bahadori M. Comparison of Total Salivary Antioxidants in Smokers and Non-smokers With \\
Chronic Periodontitis. Jundishapur Journal of Medical Sciences. 2021; 20(4):376-381. https://doi.org/10.32598/JSMJ.20.4.2549
\end{tabular}

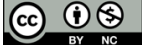

Received: 03 May 2021 Accepted: 02 Sep 2021 Available Online: 01 Oct 2021

Keywords: Chronic periodontitis Antioxidants, Smoking, Saliva

\section{ABSTRACT}

Background and Objectives Periodontitis is an inflammatory disease that involves supporting tooth structure, can be affected by risk factors like smoking, and increase the prevalence and severity of periodontal damages. Antioxidant stress to target molecule and prevent from degeneration of normal cells. This study aimed to compare the salivary total antioxidant level in smokers and non-smokers with chronic periodontitis.

Subjects and Methods A case-control study was performed in 60 chronic periodontitis patients ( 30 smokers and 30 non - smokers) in referral patients to Ahvaz Jundishapoor university of Medical Sciences, School of Dentistry. Saliva samples were collected from all subjects and the total salivary antioxidant level in these subjects measured with the spectrophotometry method in $600 \mathrm{~nm}$ wavelength. data analyzed with t-test statistical analysis.

Results A significant difference between total salivary antioxidant level in smokers and non-Smokers patients with chronic periodontitis observed $(P<0.001)$.

Conclusion This study showed decreasing in total salivary antioxidant level in the smoker- patients with chronic periodontitis compared to non-smoker patients with chronic periodontitis.

\section{* Corresponding Author:}

Leila Golpasandhagh

Address: Department of Periodontics, School of Dentistry, Ahvaz Jundishapur University of Medical Sciences, Ahvaz, Iran

Tel: +98 (905) 3096503

E-Mail: drleilagolpasandhagh@gmail.com 


\section{مقاله يزوهشى:

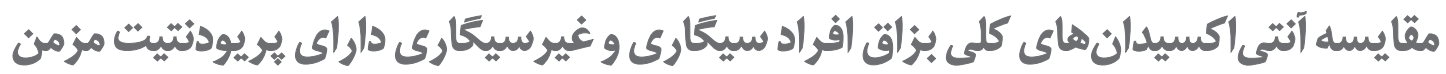

"ليلا كل بسند حق'، سيد محمد غفارى' م، مهسا بهادرى'

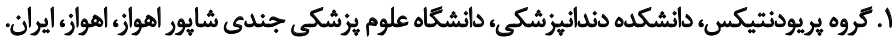

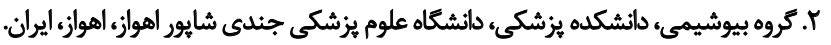

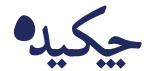

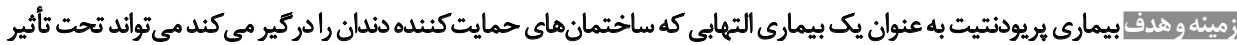

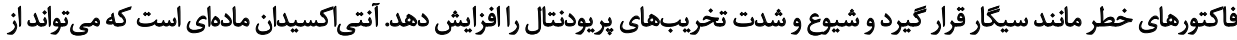

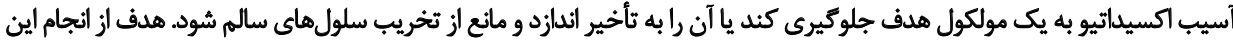

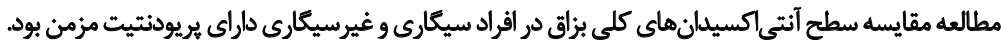

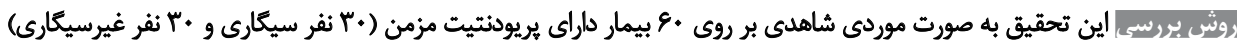

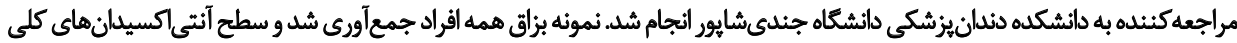

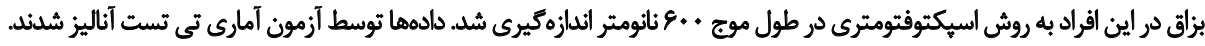

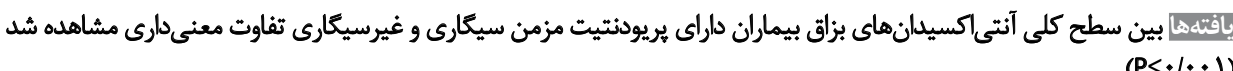

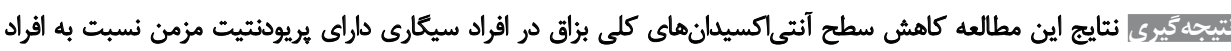

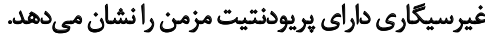

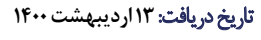

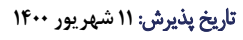
تاريخ اتتشار: 9.

بافتهاى يريودنتال ميشود [ب . []].

مetad

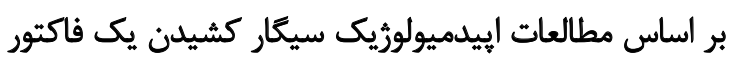

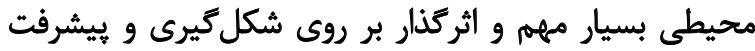

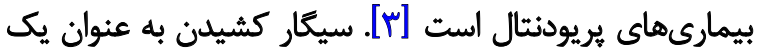

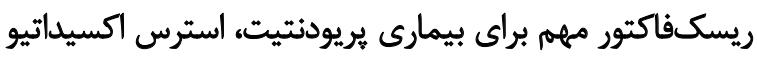

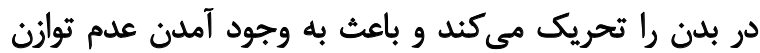

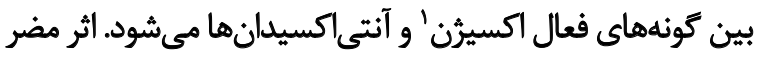

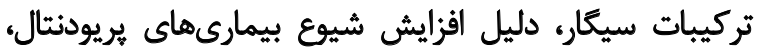

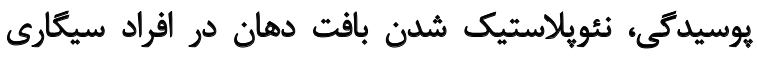

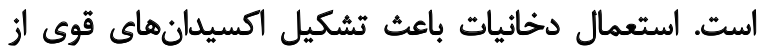

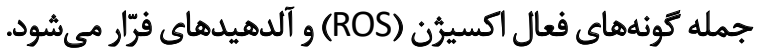

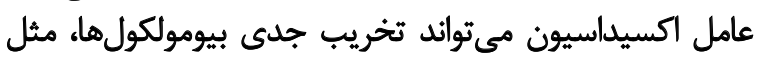

1. Reactive Oxygen Species
يريودنتيت يك بيمارى التهابي است كه استخوان آلوئول، لثه و

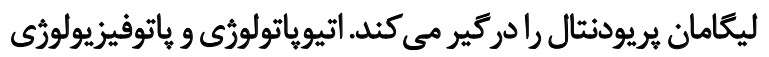

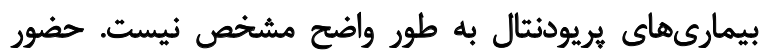

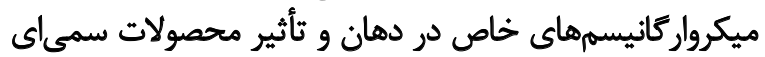

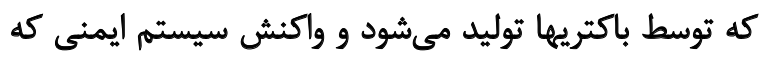
توسط عفونت باكتريايى تحريك مىشود درنهايت منجر به به

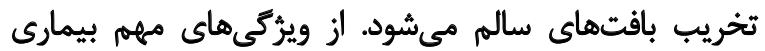

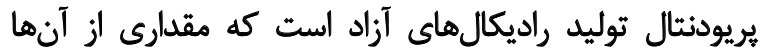
توسط باكترىها و مقدارى هم حاصل ياستهاي ايمنى است.

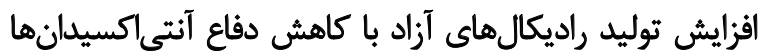

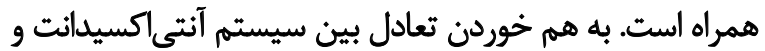

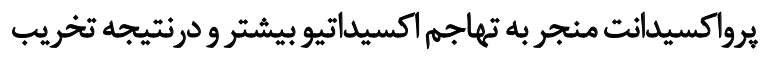

\section{-}

* : فويسنده مسئول:

ليلا كل بسند حقو

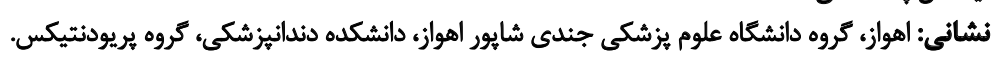

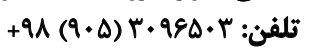

رايانامه: drleilagolpasandhagh@gmail.com 
آكادمى بريودنتولوزى آمريكا (1999) بريودنتيث مزمنشان تشخيص داده شده بود، براى اين مطالعه مورد شاهدي آندي انتخاب

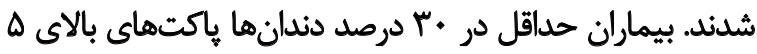

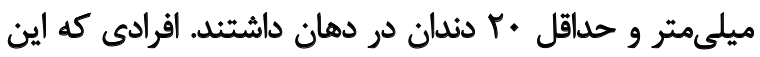

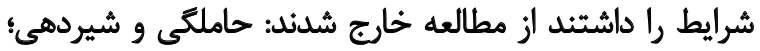

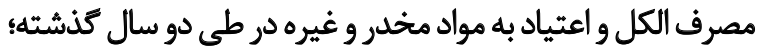

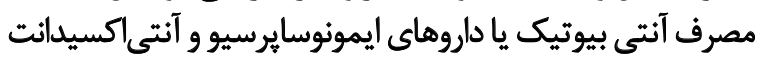

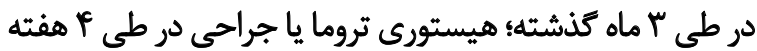

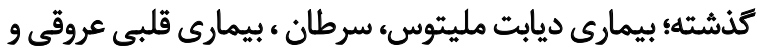

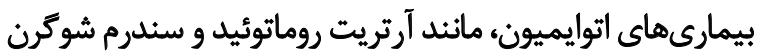

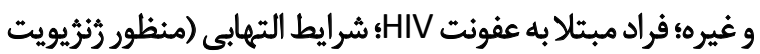

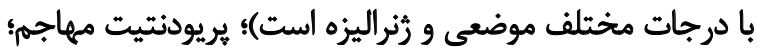

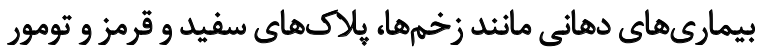
و غيره؛ انجام درمان بريودنتال در طلى بـ ماه كَذشته.

افرادى به عنوان فرد سيكارى در نظر كرفته شديند كه حداقل بردي كانخ سيكار در روز براى حداقل عرد عاد ماه بكشند.

\section{جمع آورى ثموثه بئاق}

هي از توضيح كار، از بيماران CC5 بزاق غيرتحريكى كرفته

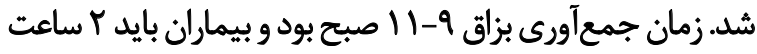

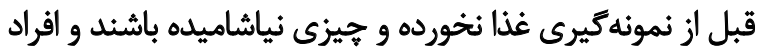

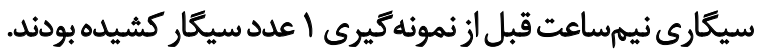

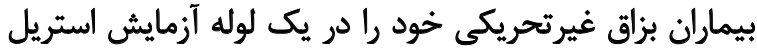

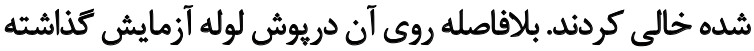

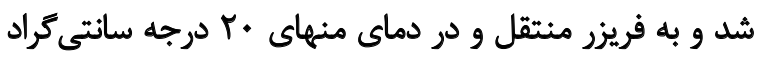

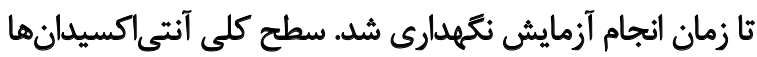
به روش اسيكتروفتومترى كيت Randox (ساخت انتلانستان)

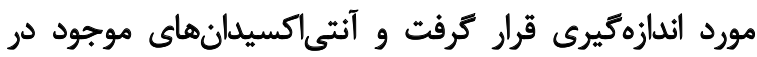

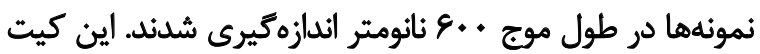

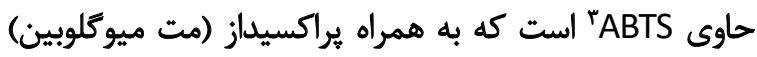

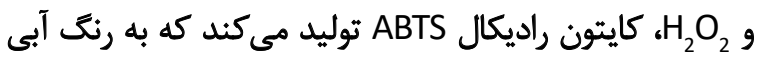

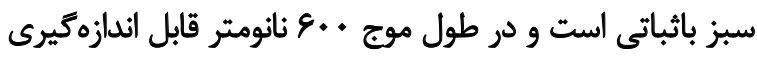

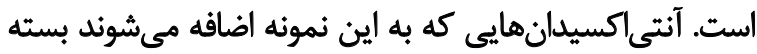

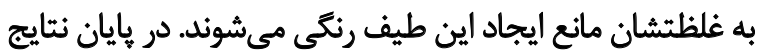

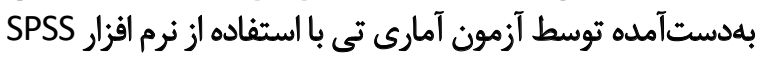

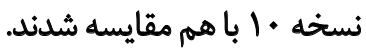

يافتهها

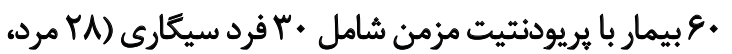

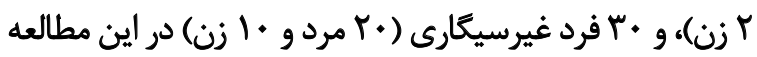

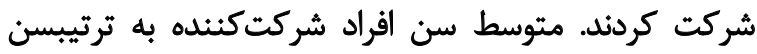

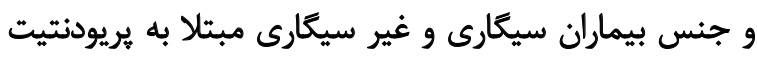

يروتثينها و آنزيمها را در يى داشته باشد كه منجر به ايجاد

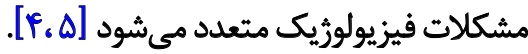
آنتىاكسيدان مادهاي است كه مي تواند از آسيب اكسيداتيو

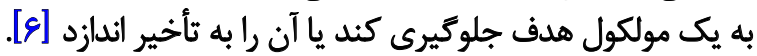

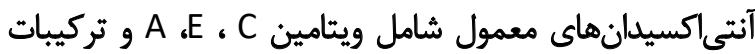

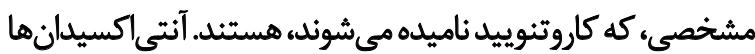

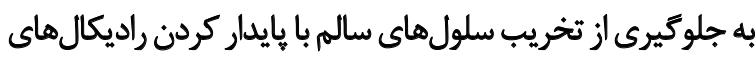

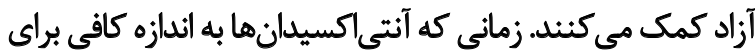

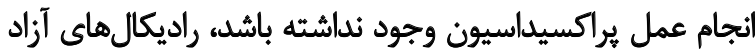

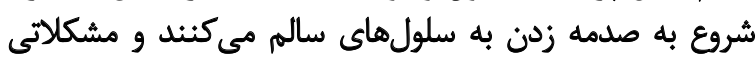

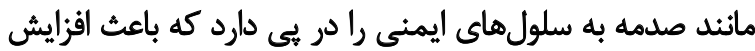

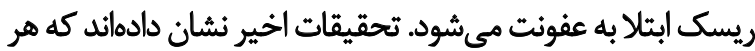

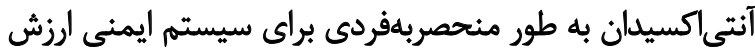

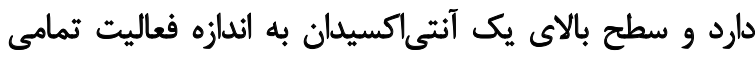

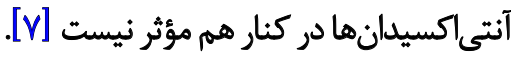
در مطالعهاى اثر سيكار كشيدن و درمان يريودنتال در

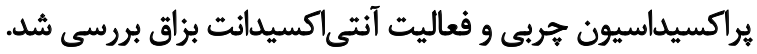

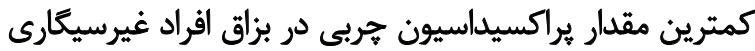

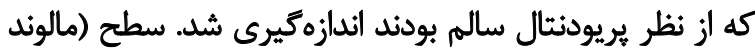

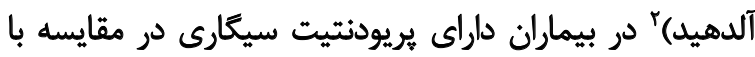

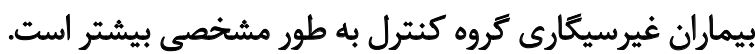

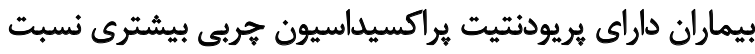

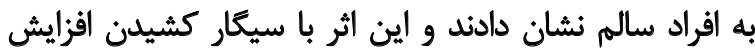

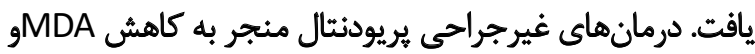
GSH-PH

$$
\text { كنترل سالم مىشود [A] }
$$

در مطالعه ديكر ظرفيت آنتى اكسيدان كلى بزاق درسيكارىهاى با بريودنتيت مزمن شديد مورد ارزيابى قرار كريكي

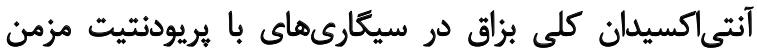

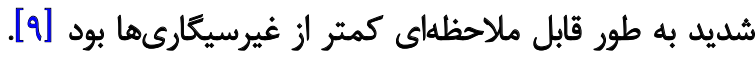

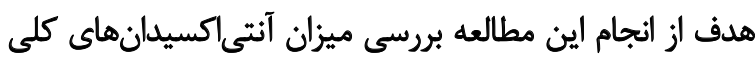

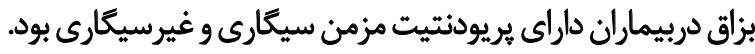

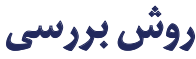

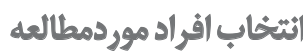

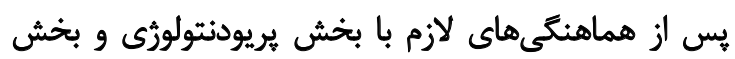

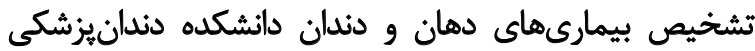

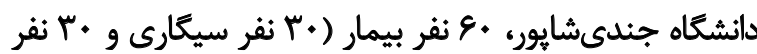

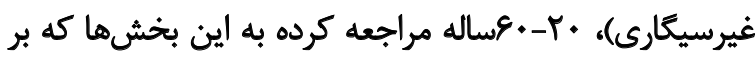

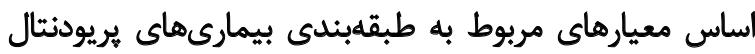


جدول (. سن و جنس بيماران سيكارى و غير سيكارى مبتلا به يريودئتيث مزمن (تعداد هر كروه: •"م)

\begin{tabular}{|c|c|c|}
\hline \multicolumn{2}{|c|}{ ميانكين |أحرافمعيار } & \multirow{2}{*}{ بيمار دهار هيريودثتيت مزمن } \\
\hline سيكارى & غيرسيكارى & \\
\hline YNY & $r+\Lambda$. & جنس (مرد بهن ن) \\
\hline$\Gamma / \Lambda+ \pm V / T$ & $P I / N+ \pm g / \pi$ & متوسط سن \\
\hline$r+/ r \pm \Delta / r$ & - & تعداد نخمهاى كشيدهشه در روز \\
\hline
\end{tabular}

جدول ז. ميزان آنتى اككسيدان كلى بزاق در افراد سيكارى و غير سيكارى

\begin{tabular}{|c|c|c|}
\hline \multirow{2}{*}{$\mathbf{P}$} & مياتئيث ثانحرافمعيار & \multirow{2}{*}{ 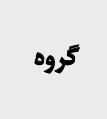 } \\
\hline & أتتىاكسيدان كلى بزاق (nmol/L) & \\
\hline \multirow{2}{*}{$<* / . .1$} & $. / R T Y \pm \cdot / M$ & سيكارى \\
\hline & V/RTVE./MU & غيرسيكارى \\
\hline
\end{tabular}

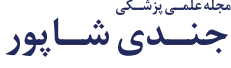

كشيدن به افزّايش استرس اكسيداتيو و عدم تعادل بين اكسيدان

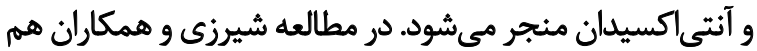

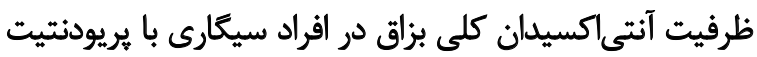

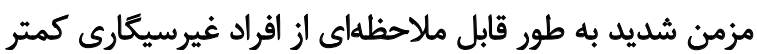

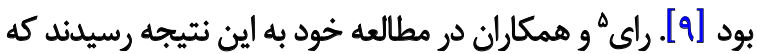

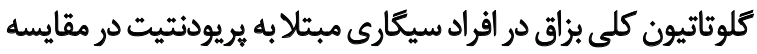

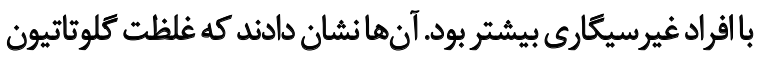

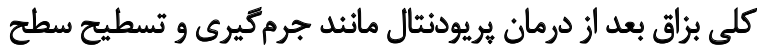

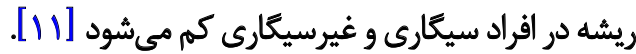
مطالعه ما به مقايسه سطح آنتى اكسيدانهاى كلى بزاق در

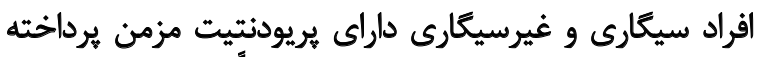

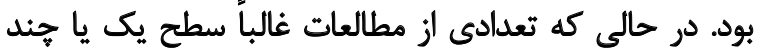

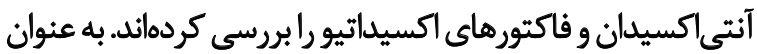

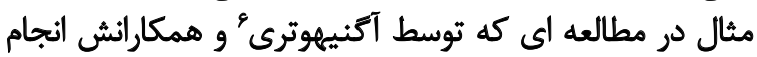

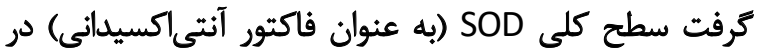

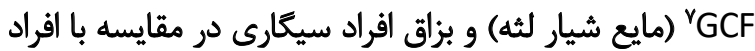

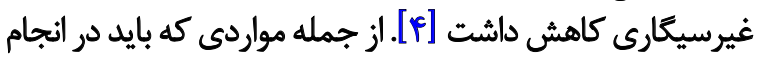

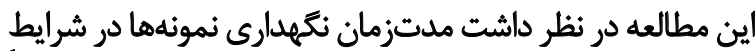

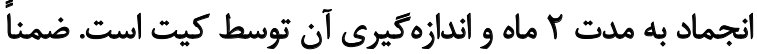

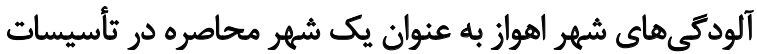

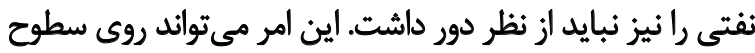
مختلف آنتى اكسيدان تأثير داشتئه باشيد.

5. Rai

6. Agnihotri

7. Gingival Crevicular Fluid
مزمن Sמr/

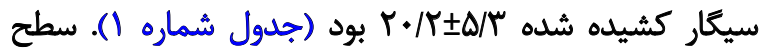

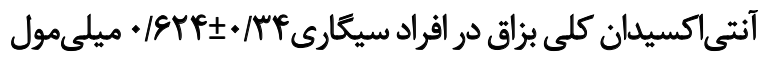

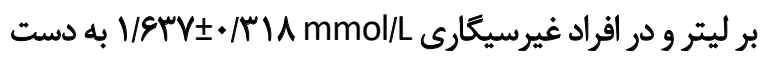

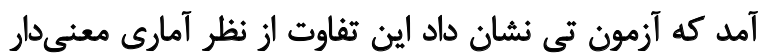

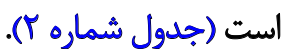

\section{ثैب}

و در اين مطالعه سطح آنتىاكسيدانهاى كلى بزاق در افراد سيكارى

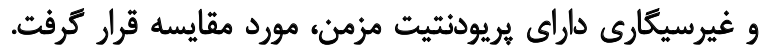

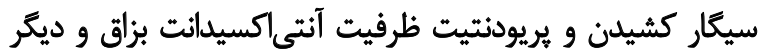

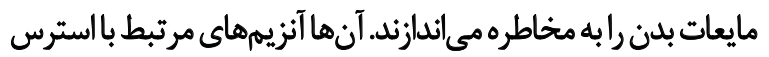

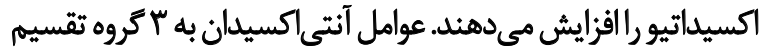

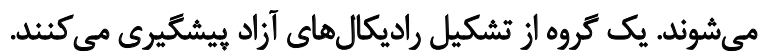

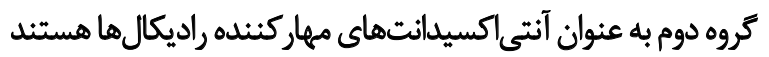

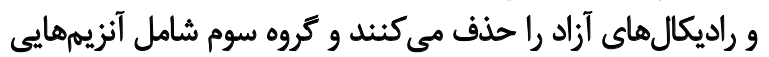
هسيتد كه DNA را ترميم مى ركنيند [.1.] در مطالعه حاضر سطح آنتىاكسيدان كلى بزاق سيكارئاريها

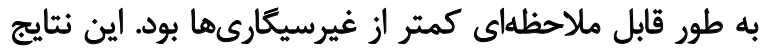

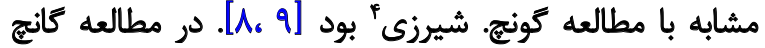

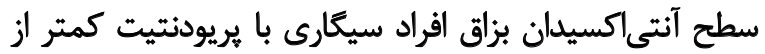

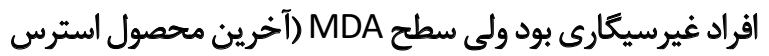

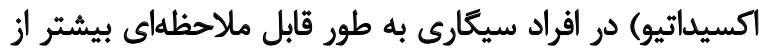
افراد غيرسيكارى بود [A]. مطالعه آنها ثابت كرد كه سيكار 


\section{تنيجلكيرى}

با توجه به نتايج مطالعه حاضر كه كاهش سطح آنتى اكسيدانها

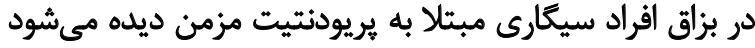

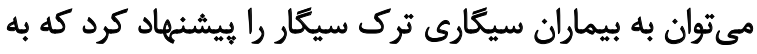

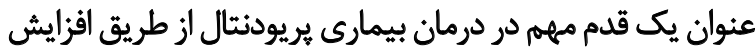
سطح آنتىاكسيدانهاست. مالاحظات اخلاقى

$$
\text { بييووى از اصول اخلاق يثوهش }
$$

اين طرح تحقيقاتى در كميته اخلاقى دانشكاهدانشكاه علوم

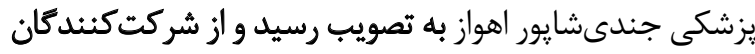

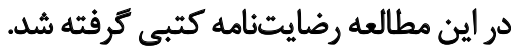

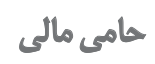

معاونت يزوهشى دانشكاه علوم يزشكى جندى إئشايور اهواز حامى مالى اين يُروهش مى دياشد.

$$
\text { مشاركت ثويسندكان }
$$

$$
\begin{aligned}
& \text { تمام نويسندكان در طراحى، اجرا و نكارش همه بخشهاى } \\
& \text { يزوزهش حاضر مشاركت داشتهاند. } \\
& \text { تعارض منافع }
\end{aligned}
$$

بنابر اظهار نويسندكان اين مقاله تعارض منافع ندارد.

$$
\text { تشكر و قلدرداني }
$$

بدينوسيله از معاونت محترم يُوهشى دانشكده دندانيزشكى

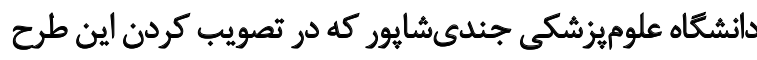

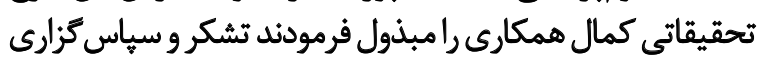

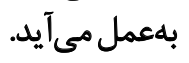




\section{References}

[1] Cutando A, Gómez-Moreno G, Arana C, Acuña-Castroviejo D, Reiter RJ. Melatonin: Potential functions in the oral cavity. J Periodontol. 2007; 78(6):1094-102. [DOI:10.1902/ jop.2007.060396] [PMID]

[2] Golusińska-Kardach E, Napierała M, Sokalski J, Kardachi H, Florek E. [Periodonta disease in smokers, and the parameters of oxidative stress (Polish)]. Przegl Lek. 2015; 72(10):584-7. [PMID]

[3] Newman MG, Takei H, Klokkevold PR, Carranza FA. Carranza's clinical periodontology. Amsterdam: Elsevier Health Sciences; 2011. https://books.google.com/ books?hl=en\&lr=\&id=BspTzxVK6-kC\&oi=

[4] Agnihotri R, Pandurang P, Kamath SU, Goyal R, Ballal S, Shanbhogue AY, et al. Association of cigarette smoking with superoxide dismutase enzyme levels in subjects with chronic periodontitis. J Periodontol. 2009; 80(4):657-62. [DOI:10.1902/ jop.2009.080545] [PMID]

[5] Rao P, Ande A, Sinha N, Kumar A, Kumar S. Effects of cigarette smoke condensate on oxidative stress, apoptotic cell death, and HIV replication in human monocytic cells. PLoS One. 2016; 11(5):e0155791. [DOI:10.1371/journal.pone.0155791] [PMID] [PMCID]

[6] Sies H. Oxidative stress: Oxidants and antioxidants. Exp Physiol. 1997; 82(2):291-5. [DOI:10.1113/expphysiol.1997.sp004024]

[7] Azzi A, Stocker A. Vitamin E: Non-antioxidant roles. Prog Lipid Res. 2000; 39(3):231-55. [DOI:10.1016/S0163-7827(00)00006-0]

[8] Guentsch A, Preshaw PM, Bremer-Streck S, Klinger G, Glockmann E, Sigusch BW. Lipid peroxidation and antioxidant activity in saliva of periodontitis patients: Effect of smoking and periodontal treatment. Clin Oral Investig. 2008; 12(4):345-52. [DOI:10.1007/s00784-008-0202-z] [PMID]

[9] Shirzaiy M, Rigi Ladiz MA, Dalirsani Z, Dehghan Haghighi J, Nakhaii AR. Evaluation of salivary total antioxidant capacity in smokers with severe chronic periodontitis. Int J High Risk Behav Addict. 2017; 6(3):e59486. [DOI:10.5812/ijhrba.59486]

[10] Battino $\mathrm{M}$, Bullon $\mathrm{P}$, Wilson $\mathrm{M}$, Newman $\mathrm{H}$. Oxidative injury and inflammatory periodontal diseases: The challenge of antioxidants to free radicals and reactive oxygen species. Crit Rev Oral Biol Med. 1999; 10(4):458-76. [DOI:10.1177/1045441199 0100040301] [PMID]

[11] Rai B. Total salivary glutathione levels: Periodontitis in smoker and non-smoker. Adv med Dent Sci. 2008; 2(2):47-9. http:// arnmsmb.com/old/amds/2008/47-49.pdf 